"The specialist in communications, oral, written, and visual, is an important member of the modern health team. This fact is evident in the growing number of these personnel who are taking their places on the staffs of voluntary and professional health organizations and of official agencies at all levels of government."

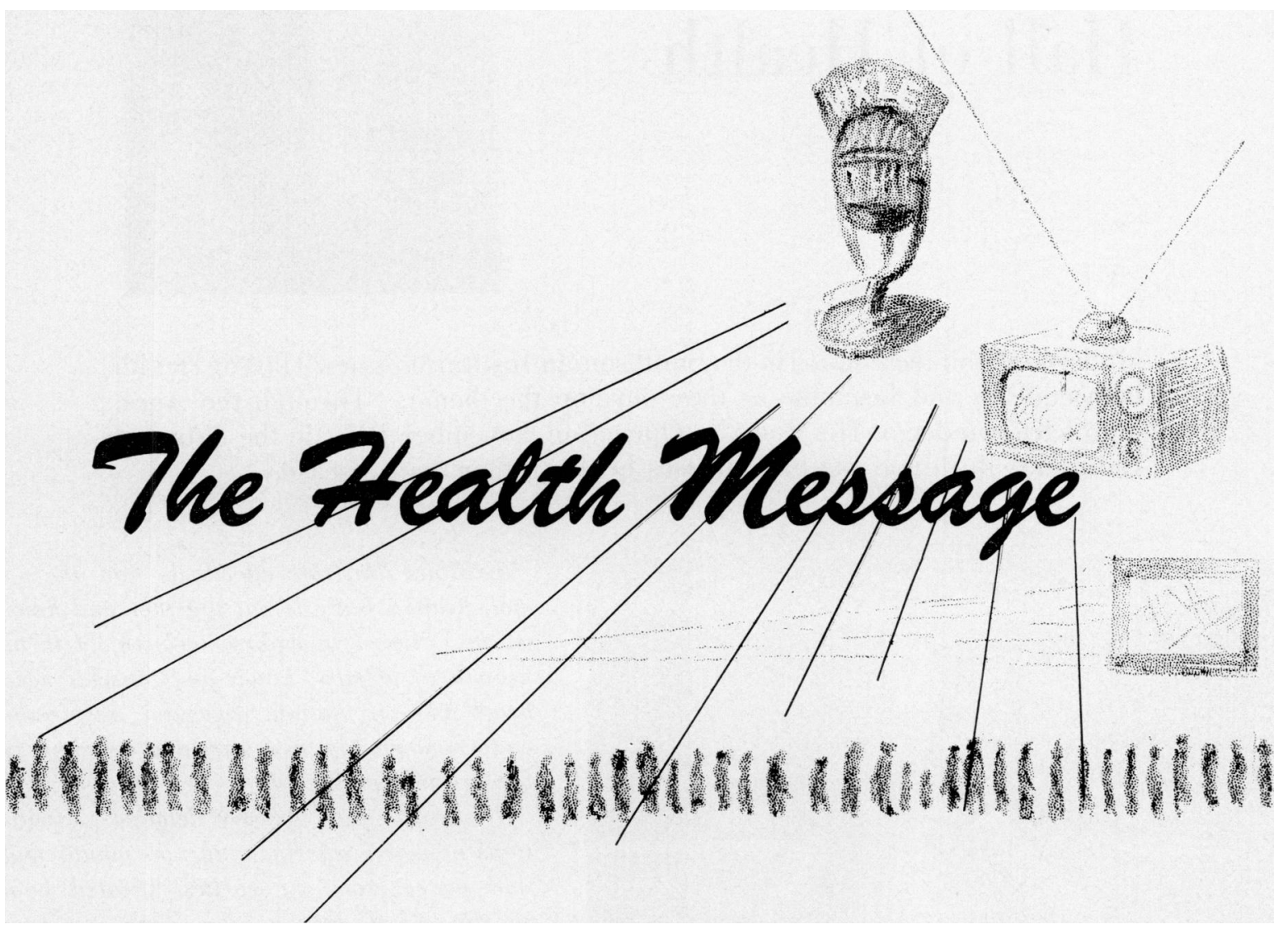

JOHN D. PORTERFIELD, M.D.

A

HALL OF HEALTH offers an excellent device for imparting knowledge about health and disease. We in the Public Health Service are proud to have had a part in the rebirth of a Hall of Health in the great Smithsonian Institution. The information on human anatomy and physiology which it presents should have a substantial impact on the knowl-

Dr. Porterfield is Deputy Surgeon General of the Public Health Service. The address was delivered at the ceremony opening the Hall of Health, Smithsonian Institution, Washington, D. C., November 2, 1957. edge and behavior of the many thousands of visitors to the Institution each year.

Within the limits of time and space, the exhibit is probably among the best devices man has invented to communicate facts and ideas about the physical world. At its best, it combines the advantages of language and visual presentation in a specific and coordinated message with a high teaching potential. From the scratched stone drawings of ancient times to the sophisticated three-dimensional clay models of today, exhibits have been used to teach and to stimulate interest.

Certainly, the exhibit has long been an im- 


\section{Hall of Health}

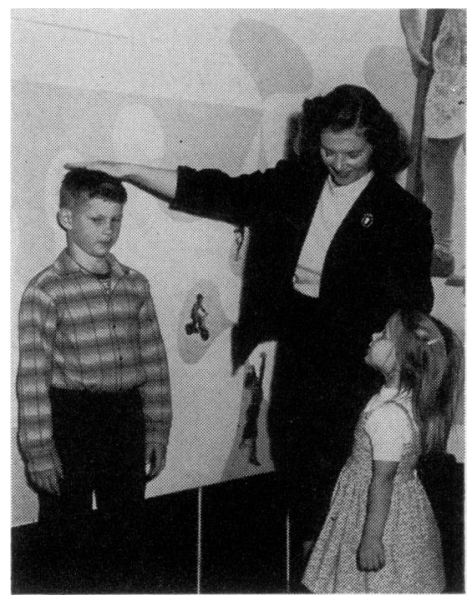

Modern exhibit techniques in the Smithsonian Institution's new Hall of Health both educate and fascinate as they develop the theme: "Through the Ages, Man's Knowledge of His Body." Opened in November 1957 in the Arts and Industries Building, the hall stresses health rather than disease.

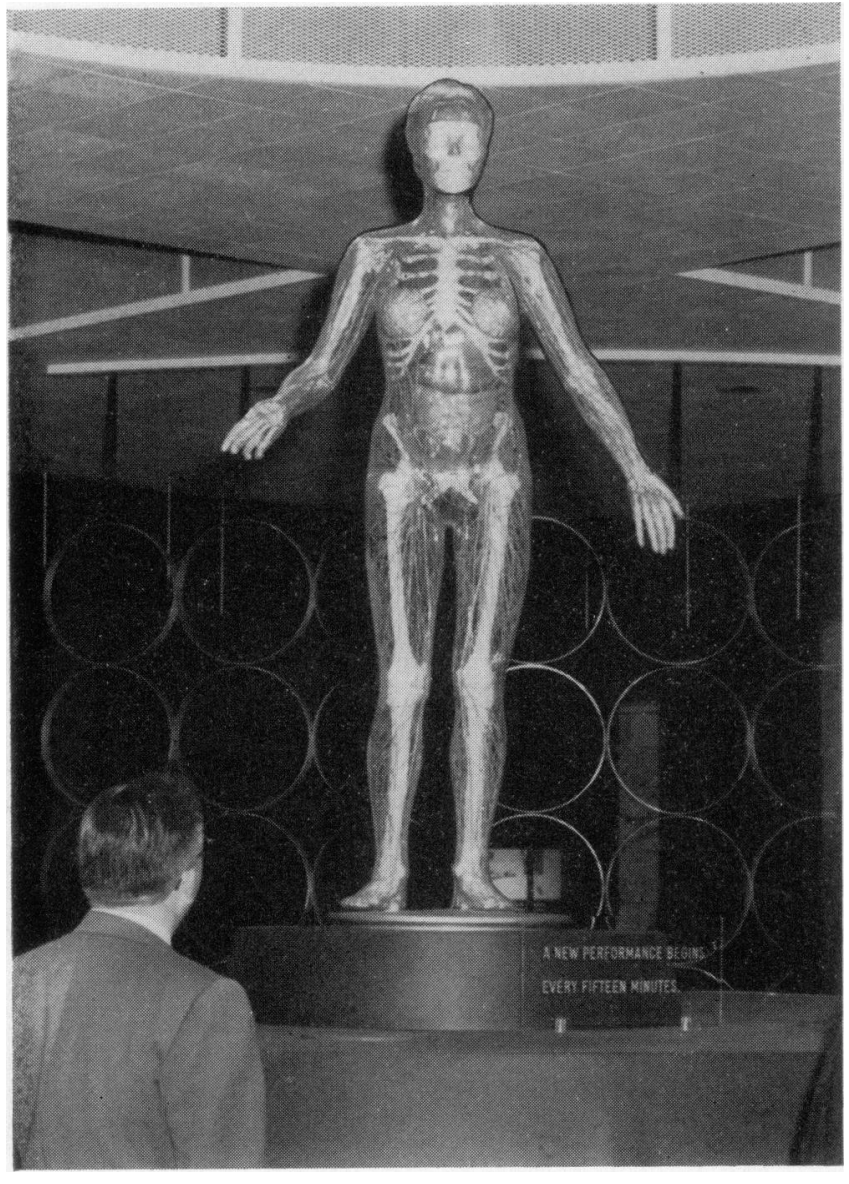

Exhibits illustrate effectively how the normal, healthy body is put together and how it works. Stages in embryo growth, birth and growth of a baby, bones and muscles, teeth, heart and circulation, digestion, respiration, endocrine glands, eye, ear, and nervous system are all represented.

Historical units display detailed reproductions of votive offerings, ancient manuscripts, and pages from the earliest printed books showing embryology, the skeleton, heart, brain, and digestive system as our ancestors knew them.

$A$ center of attraction is the transparent figure of a woman (left) which, through electronics, light, and sound, shows the site and explains the function of major organs in the body. Other pushbutton exhibits reveal the inside of the human heart, anatomy of the tooth, site and action of endocrine glands, and brain function of a baseball player at bat.

The popular wall exhibit, "Growing, Growing, Grown," has a series of cutout forms of varying sizes (above) for determining typical heights of children at years 3, 6, 9, 12, and 15. Activities characterizing each age are illustrated in photographs mounted at appropriate intervals along the cutout series. 
portant means of communication in the fields of science and medicine.

The first American scientific exhibit as it is known today was displayed at the annual meeting of the Indiana State Medical Association in 1899. It consisted of a large collection of pathological specimens prepared by two Indianapolis physicians. It was such a great success that the two physicians displayed it the same year at the meeting of the American Medical Association held in Columbus, Ohio. Since 1900, the scientific exhibit has been an official part of the annual meeting of that association.

Today every sizable group in the health field gives the exhibit equal status with scientific papers and other original presentations.

But exhibits also have broader and more general uses. With the complex growth of our society, it has become necessary to use the exhibit not only as a professional and scientific tool but also as a means of reaching the general public. In 1904 the first tuberculosis exhibit for the general public was developed in Baltimore. It attracted nationwide attention, and was soon followed by a similar display at the American Museum of Natural History in New York where it was seen by thousands of visitors. The following year, the exhibit toured the Eastern States, under the sponsorship of the newly organized tuberculosis association and the guidance of one of the early disciples of visual health presentation, Evart G. Routzahn.

Since that time, the health exhibit has become a staple of numerous meetings and shows, and particularly of State and county fairs in rural areas. The modern era, however, ushered in many new and wondrous communications media : films, filmstrips, radio, and television. In comparison with these devices, the exhibit was thought to be archaic as a health education technique. Enthusiasm for exhibits seemed to wane.

Yet in 1939-40 the special hall of "Medicine and Public Health" of the New York World's Fair drew an estimated audience of $71 / 2$ million people. A popular health fair organized in 1954 in Miama, Fla., by the American Medical Association, with exhibits of the major professional, voluntary, and governmental health agencies of this Nation, attracted about 50,000 visitors in 4 days. There were comparable crowds at subsequent health fairs in such cities as Los Angeles, Cincinnati, and Oklahoma City.

I believe this is indicative of a number of things, but primarily of the tremendous popular interest in health matters. A recent survey, for example, revealed that newspaper readers wanted to see more articles on health than on any other single subject. Most of the major mass circulation magazines have special science and health departments. Popular pamphlets on health and hygiene reach millions of readers each year.

This reservoir of interest and awareness represents a challenge to us in public health as it does to those in the broad field of education.

As specialization in medicine and science becomes narrower and deeper, as new knowledge emerges from laboratories and research institutions, and as modern life becomes increasingly complex, it is essential that we rely more and more on easily understood methods of communication.

Since World War II, the volume of medical research in this country has increased about fivefold. We are beginning to make inroads on the problems posed by chronic illness and an aging population. There are things that can be done to treat some forms of heart disease, tests of value in diagnosing some forms of cancer, and new techniques in the treatment of mental illness. Thus, the pool of information which demands interpretation and application continues to grow.

To us in public health, this means that the specialist in communications, oral, written, and visual, is an important member of the modern health team. This fact is evident in the growing number of these personnel who are taking their places on the staffs of voluntary and professional health organizations and of official agencies at all levels of government.

For many years, for example, the Federal Government has made use of exhibits to help convey useful information of all kinds, both to professional groups and to the general public. In the health field, the medical museum was started by the Army during the Civil War. For almost a century, this nearby neighbor of the Smithsonian has made significant contri- 
butions to medical knowledge through its exhibits. The Public Health Service, too, has found this technique of communication invaluable, as have State and local health departments.

Today's challenge is no less great for such great institutions as the Smithsonian. The exhibit will always have a place in health education. As long as a youngster's curiosity is whetted by a visual presentation of the marvelous mechanism that is the human heart, then exhibits have no peer as a health teaching resource. As long as there is zest for knowledge, then there is a need for new and better and more vivid ways of bringing that knowledge to people.
Certainly we need to know more about how people learn through visual experience. We need to know how to improve the presentation of facts and information and arguments through visual means. We need to know how to take advantage of the "teachable moment" that a superior kind of exhibit can make possible.

Bruno Gebhard, director of the famous Cleveland Health Museum, has called a permanent health museum a "people's university," where visitors may see, study, and learn at their own pace and in their own way. In this new Hall of Health, the Smithsonian Institution has a "people's university" offering guidance to better health for more Americans.

\section{Divorce and Annulment Data Collection Improved}

An improved system of collecting statistics on divorce and annulment of marriage was adopted January 1, 1958, by the Public Health Service. A divorce and annulment registration area has been set up as a start toward obtaining figures on divorces and annulments as reliable and comprehensive as on births and deaths.

Since some States do not collect statewide figures on divorces and annulments, national statistics are based partly on estimates.

The new system not only provides a more accurate count, but also includes additional social and economic data on family breakdowns, information of value to courts, health and welfare agencies, and other groups dealing with dependency, juvenile delinquency, mental illness, and related problems.

The uniform data will be collected by the National Office of Vital Statistics, in cooperation with 14 States and 3 Territories: Alabama, Georgia, Idaho, Iowa, Montana, Nebraska, Oregon, Pennsylvania, South Dakota, Tennessee, Utah, Virginia, Wisconsin, Wyoming, Alaska, Hawaii, and the Virgin Islands. 